\title{
Perspectivas para a regulação das nanotecnologias aplicadas a alimentos e biocombustíveis
}

\section{Prospects for the regulation of nanotechnology applied to food and biofuels}

\author{
Wilson Engelmann \\ Universidade do Vale do \\ Rio dos Sinos (UNISINOS), \\ São Leopoldo, RS, Brasil \\ wengelmann@unisinos.br \\ Andrea Aldrovandi \\ Universidade de Caxias do \\ Sul (UCS), Caxias do Sul, \\ RS, Brasil \\ Airton Guilherme \\ Berger Filho \\ Universidade de Caxias do \\ Sul (UCS), Caxias do Sul, \\ RS, Brasil
}

\begin{abstract}
RESUMO
O artigo aborda as possibilidades de regulação das nanotecnologias aplicadas aos alimentos e aos biocombustíveis. Nesse sentido, busca-se estudar os riscos e perigos advindos dessa junção, bem como algumas alternativas regulatórias, tomando-se como referência fórmulas alternativas não derivadas do Estado e do Poder Legislativo, mas oriundas de órgãos internacionais, das empresas envolvidas e de programas de cumprimento voluntário das regras e princípios, já vigentes, mas não diretamente relacionadas às nanotecnologias. Com isso, o estudo aponta possibilidades de o Direito ingressar nas perspectivas abertas pela Revolução Nanotecnológica, fomentando o cumprimento de normas que tenham como principal foco a saúde e a segurança do ser humano e a preservação do meio ambiente.
\end{abstract}

PALAVRAS-CHAVE: nanotecnologias, alimentos, biocombustíveis, regulação

\begin{abstract}
The article discusses the possibilities for nanotechnology regulation applied to food and biofuels. In this sense, we seek to study the risks and hazards of this junction, as well as some alternative regulatory taking as reference formulas, not derived from the State and the Legislature, but coming from international agencies, the companies involved and programs voluntary compliance with the rules and principles already in place, but not directly related to nanotechnology. Thus, the study address law possibilities to join the perspectives opened by the Nanotechnology Revolution, encouraging the fulfillment of standards which have mainly focused on the health and safety of human and environmental preservation.
\end{abstract}

KEYWORDS: nanotechnology, food, biofuels, regulation 


\section{Introdução}

As nanotecnologias representam uma das mais intrigantes revoluções tecnocientíficas já desencadeadas pelo ser humano. Elas podem ser encontradas nos mais variados setores da produção e comercialização na atualidade, trazendo características e propriedades inovadoras e sem precedentes na história científica da humanidade. As nanotecnologias, conectadas às perspectivas tecnocientíficas, deixaram o plano teórico e ficcional, superando a fase de investigação sobre suas possíveis aplicações. Na fase atual, a força e o valor do prefixo nano já estão reconhecidos no mercado, gerando, como resultado, uma elevada projeção de rendimentos no âmbito industrial e comercial.

Dada a ausência de marco regulatório, pretende-se avaliar as possibilidades para a regulação, na estruturação de formas plurais de governança dos riscos da nanotecnologia aplicada aos alimentos e aos biocombustíveis. 0 momento é desafiador para o Direito, que precisará modificar e realinhar as suas formas de regulação, além de se abrir para as demais áreas do conhecimento, buscando desenvolver transdisciplinarmente a gestão dos riscos nanotecnológicos.

Dentro desse cenário, este artigo enfrenta a problemática das contradições e aproximações e possíveis convergências entre diferentes formas de regulação das nanotecnologias, no desenvolvimento de alimentos e biocombustíveis: a regulação tradicional (command and control regulation) e os instrumentos regulatórios alternativos da soft law voltados para a atuação do setor privado.

A hipótese aponta para a valorização de manifestações de normas sociais não catalogadas entre as fontes tradicionais do Direito e resultantes de processos decisórios envolvendo atores não estatais, como organizações não governamentais, instituições de pesquisa, entidades financiadoras de investigação, empresas, organizações internacionais etc.

\section{Metodologia}

Como métodos de abordagem o trabalho utilizou o método comparativo, histórico, estrutural e estudo de caso. As técnicas de pesquisa foram a pesquisa e revisão bibliográfica associada à pesquisa documental, que envolve a análise de documentos legislativos e publicações de órgãos internacionais vinculados à regulação em matéria de nanotecnologias.

Adotou-se a perspectiva teórico-dialética do Direito desenvolvida por François Ost e Michel van de Kerchove. 1 Na publicação "De la pyramide au réseau? Pour une théorie dialectique du droit", os autores propõem a reflexão sobre mudanças estruturais no sistema jurídico, que passa por uma transição paradigmática ainda incompleta, na qual a verticalidade linear da hierarquia piramidal do ordenamento jurídico e a regulamentação por parte do Estado tendem a ceder espaço para uma rede complexa, de regulação e governança, que envolve uma pluralidade de atores estatais e não estatais.

O Direito, em diversos setores, passa por um momento de transformação no qual se amplia a influência da regulação transnacional, regulação técnica e da autorregulação privada em relação ao Direito predominantemente estatal. A concepção positivista, monista, centrada na territorialidade do Estado, fechada enquanto um sistema formal e hierárquico representado pela metáfora da pirâmide 2 , cede espaço para novas estruturas do Direito. Em questões envolvendo temas emergentes como direitos humanos, novas tecnologias, meio ambiente e comércio internacional percebe-se uma pluralidade de formas de regulação, que pode ser descrita como uma rede complexa que envolve tanto as tradicionais normas estatais obrigatórias, providas de sanção, como novas manifestações do Direito, compostas por normas não obrigatórias conhecidas como soft law, desvinculadas dos processos formais de produção legislativa. Também são perceptíveis mudanças estruturais importantes no exercício e legitimação do poder, especialmente em setores emergentes como na regulação das novas tecnologias. Nesse movimento, o monopólio estatal sobre a condução do Direito e da gestão dos bens públicos (o governo) perde espaço para o pluralismo jurídico e para a diversidade de atores sociais (empresas, organizações de representação profissional, instituições de normalização e certificação, organizações não governamentais) e na condução dos processos decisórios (a governança).

\section{Fundamentação Teórica}

\section{A convergência tecnocientífica e a geração de novos desafios: criando um novo (?) mundo na escala nanométrica}

A tradição mostra que a Ciência estava moldada a partir de determinadas características, como: buscar conhecer o mundo circundante, a fim de "[...] descrevê-lo, interpretá-lo, compreendê-lo, explicá-lo e, no melhor dos casos, predizer a priori os acontecimentos que vão ocorrer, e retrodizer o que ocorreu, explicando-o melhor" 3. Esse paradigma científico, no entanto, gradativamente foi sofrendo modificações, especialmente no modo de operar e produzir o conhecimento científico, na medida em que agora é incentivada a ciência como caminho para o desenvolvimento tecnológico, reduzida à lógica do produtivismo, transformada em tecnociência, cada vez mais orientada pelas leis do mercado. Diferentes valores norteiam a motivação da pesquisa, de modo que "para um cientista o conhecimento é um fim em si, enquanto que para um tecnocientista é um meio para buscar objetivos de outra ordem" ${ }^{3}$. Inclusive, a maior parte das instituições responsáveis pelo fomento à pesquisa tende a reproduzir a lógica produtivista, que dá preferência às investigações aplicáveis ao desenvolvimento tecnológico. Há constante e crescente busca pela inovação tecnológica, promovendo o surgimento de novos processos e produtos, a fim de se atenderem as demandas do mercado consumidor.

Por conta dessas mudanças, a ciência contemporânea já não se categoriza "[...] como um discurso ou uma cosmovisão, 
senão uma atividade consciente e deliberada e que, ademais, se desenvolve em equipes, geralmente grandes equipes, que incluem interesses e forças tão distintas como a teoria, a prática, a administração, por exemplo" "4. A atitude tecnocientífica é muito mais agressiva, pois não é contemplativa e exploratória, mas interventiva e transformadora. Podendo dizer-se que pretende reconstruir o mundo em que se vive, "invadindo" todos os recantos da natureza, que parece ser um obstáculo a ser transposto. Dentro desse contexto nasce a nanotecnociência buscando sinalizar que não existem ciência e tecnologia separadas, mas confirmando uma união muito forte concentrada no mundo nanoescalar. Destaca-se que não se busca "[...] descrever os processos da natureza na escala nano, mas transformar ativamente a natureza sobre a qual trabalha". Vale dizer que a nanociência não se apresenta como uma ciência no sentido tradicional da palavra, mas como uma "ciência de fronteira" 4. Portanto, diante de uma "ciência de fronteira", cabe indagar: qual a fronteira (ética) dessa ciência? Essa pergunta se faz necessária, pois ela é uma alternativa para promover a convergência entre varias ciências: nanociência, as ciências que trabalham com a vida e a partir dela, as ciências da informação e as ciências do conhecimento, ou seja, as cognitivas. Além da mencionada pergunta, cabe mais uma: como a Ciência do Direito dará conta dessa revolução tecnocientífica? Aí o ponto central deste artigo: buscar alternativas criativas e flexíveis para a construção de respostas jurídicas, sem depender necessariamente da atividade estatal ${ }^{5}$.

$\mathrm{Na}$ era da inovação nanotecnológica, os Direitos Humanos se apresentam como uma preliminar ética fundamental (de proteção) para delimitar o campo das pesquisas em escala nano e da construção dos marcos regulatórios. "Hoje, nanotecnologia, no uso amplo do termo, refere-se a tecnologias em que produtos apresentam uma dimensão (in)significante, isto é, menos que $1 / 10$ de mícron, cem nanômetros ou cem bilionésimos de metro" ${ }^{6}$. 0 Direito precisa se preparar para participar da consolidação dessa Revolução Tecnocientífica ${ }^{7}$, renovando os seus pressupostos e preparando-se para construir respostas criativas aos novos direitos e desafios que esse cenário de inovação trará à sociedade. E não é só isso. A nanotecnologia, além de interagir fortemente com a natureza, promoverá mudanças no corpo humano, que passará a ser, "[...] ao mesmo tempo, formado pela tecnologia e criador de tecnologia, gerando continuamente novos referenciais de absorção da experiência imediata. A tecnologia é constitutiva do homem". A interface cérebro-máquina proporciona experiências inusitadas, permitindo-se afirmar: "[...] a técnica tornou-se autotélica, ou seja, um fim em si mesma, e a sociedade se debate com questões novas desencadeadas por esta realidade - engenharia genética, nanotecnologia, pesquisa com células tronco etc.". Isso acaba promovendo um nível preocupante de "[...] descompasso entre a moral (construída coletiva e lentamente) e o ritmo do avanço técnico. Corre-se o risco de se embarcar em uma tecnocracia totalitária, com a ciência evoluindo na busca de desempenhos-limite, em detrimento da descoberta de verdades que produzam sentido para a vida" ${ }^{8}$. Para dar conta dessas diversas facetas da complexidade inaugurada pela era da tecnociência e exemplificada por meio das nanotecnologias, o movimento da especialização da ciência parece que precisará ser revisto. "O processo de especialização da ciência, iniciado no século XIX e completado no século $X X$, resultou na formação de cientistas especializados em campos do saber cada vez mais restritos" 9 A convergência tecnológica entre nano-bio-info-cogno parece que não se coaduna com essa especificação do saber científico. Pelo contrário, exigirá fórmulas transdisciplinares para a construção do saber no cenário tecnocientífico. Especialmente o Direito deverá abrir-se a essa perspectiva transdisciplinar, a fim de conseguir estabelecer o desenho de marcos normativos adequados sociopolítico-ético-juridicamente.

Há fortes evidências, conforme visto, de que efetivamente as nanotecnologias trarão desafios significativos à construção de um novo mundo, pois, na caracterização dos nanomateriais, ou seja, dos materiais criados na escala nano e a partir da intervenção humana, observam-se duas características: a) quanto menor for a área superficial, maior será a concentração de átomos nessa superfície; b) o efeito quântico: na escala nano, a ligação entre os átomos é diferente, pois há a presença de níveis de energia de orbitais partilhados, produzindo alterações nas propriedades elétricas, magnéticas, térmicas, mecânicas, químicas, óticas etc ${ }^{10}$.

Essas duas características indicam um conjunto de novidades trazidas pelas nanotecnologias. Por que utilizar a expressão no plural? Trata-se de um conjunto variado de tecnologias que possibilitam a pesquisa e a produção de objetos na escala nano. A sua utilização poderá estar presente na indústria dos cosméticos, medicamentos, alimentação, vestuário, entre outros.

\section{Abrindo espaços para a construção dos marcos regulatórios sobre as nanotecnologias aplicadas aos alimentos e biocombustíveis}

As questões regulatórias perpassam diversas áreas do conhecimento envolvidas com as nanotecnologias. Elas representam o mais recente desafio a nossa capacidade de equilibrar o progresso tecnológico com a proteção da saúde humana e do meio ambiente. $O$ cenário é familiar: a tecnologia avança rapidamente e oferece um enorme potencial para o bem social, mas apresenta uma incerteza substancial em matéria de riscos para a saúde humana e ambiente ${ }^{11}$, onde se inserem os alimentos e os biocombustíveis.

No entanto, as questões que envolvem os riscos e as suas diferenciações do perigo são fundamentais, pois elas repercutirão nas formulações regulatórias. 0 risco poderá ser vislumbrado como uma consequência incerta relacionada a algum evento ou atividade a partir de valores humanos. Assim, o risco apresenta uma dimensão social, envolvendo também a sua percepção pública e os níveis que o ser humano está disposto a correr. Talvez aqui esteja um ponto fundamental para a antecipação de eventuais riscos envolvendo as nanotecnologias, a partir de três componentes: avaliação do risco, gestão do risco e a comunicação do risco ${ }^{12}$. A esses três elementos, que 
se encontram intimamente interligados, é preciso adicionar também dimensões do risco, a saber, a probabilidade de um evento ocorrer e a magnitude de suas consequências, o que pressupõe a inserção desses aspectos nesse cenário. Portanto, a decisão que será tomada é o resultado final dessa equação na construção do risco. Há uma distinção entre risco e perigo, pois aquele considera também o potencial de exposição. O perigo isoladamente não constitui "risco": deve-se ter tanto perigo quanto potencial de exposição para a caracterização do risco à saúde ${ }^{13}$.

A questão dos riscos também se apresenta de várias outras ordens, podendo-se dizer que as nanotecnologias promovem o desenvolvimento de problemas sistêmicos, por dois motivos: a) as novas tecnologias (onde estão as nanotecnologias) influenciam as estruturas econômicas e políticas e muitas vezes levantam questões relacionadas aos valores e cultura da sociedade, como a concepção sobre a natureza, a percepção sobre a privacidade, suas atitudes em direção ao controle do poder de decisão sobre a continuação ou não das pesquisas e comercialização de produtos e controle pessoal, além das perspectivas sobre a justiça distributiva; b) os caminhos estruturais da sociedade por meio de políticas e instituições para suportar, regular e julgar a segurança das tecnologias têm uma forte responsabilidade para dirigir esse desenvolvimento ${ }^{14}$. Com esses aspectos, constata-se que, além dos possíveis e eventuais efeitos toxicológicos, as nanotecnologias poderão gerar impactos sociais e políticos na sociedade, os quais ainda estão em fase de discussão e percepção mais incipiente do que a primeira categoria de riscos. Esses impactos são tão ou mais importantes que os efeitos toxicológicos e também precisam ser percebidos e regulados pelo Direito.

Ao se fazer um recorte sobre os nanoalimentos pode-se incluir, nessa definição, não só alimentos e bebidas que têm nanopartículas em sua composição, mas também tudo o que entrar em contato com alimentos e bebidas, como rações, vacinas, pesticidas, embalagens etc. São exemplos de nanoalimentos: a) nanopartículas e nanocápsulas que são agregadas aos alimentos e bebidas com o objetivo de mudar seu sabor e a textura (já presentes no mercado, em marcas líderes); b) nanopartículas adicionadas na ração de frangos, com efeitos antibióticos; c) pesticidas, que podem facilmente ser absorvidos por plantas; d) vacinas para tratamento de peixes; e) embalagens de alimentos, com o objetivo de ampliar a validade, controlar variação de temperatura, proteger alimentos contra fungos e bactérias etc $^{i}{ }^{15}$. É grande a variedade de materiais utilizados em nanoalimentos. A nanoprataii ${ }^{16}$, por exemplo, é muito utilizada por seu efeito antibacteriano. Produtos com nanoprata já estão no mercado: são alimentos, utensílios de cozinha, refrigeradores ou embalagens para guardar alimentos.

Outros materiais podem ser citados: o nano-selênio está sendo utilizado como aditivo que intensifica os efeitos do chá verde; o nanocálcio é objeto de patente que pretende sua utilização em gomas de mascar. Sais de nanocálcio e nanomagnésio são utilizados como suplementos alimentares ${ }^{17}$; nanotubos do carbono iii 18 estão sendo desenvolvidos para criação dos mais poderosos inseticidas e fungicidas e pesquisadores afirmam a possibilidade de revolução na produção de alimentos e também vegetais para a produção de biocombustíveis ${ }^{19}$. Nesse cenário, cabe ainda inserir o Relatório da OECD que aponta inovações no setor agrícola envolvendo a decodificação e análise de DNA, a qual poderá capacitar agroempresas a prever, controlar e melhorar a produção. Com tecnologia para manipulação de moléculas e átomos de alimentos, a indústria alimentar teria poderoso método para produzir com qualidade e precisão, a baixos custos, melhorando a sustentabilidade. A combinação de DNA e nanotecnologia pode gerar novos sistemas de nutrição com o objetivo de carrear substâncias a partes específicas do corpo humano. São os chamados "OAM - Organismos Atomicamente Modificados", que têm o potencial de causar debate ainda mais intenso do que os OGMs ${ }^{20}$.

É justamente nesse cruzamento entre as nanotecnologias e os vegetais que se insere a produção de biocombustível. Há uma aposta muito grande na biotecnologia para a produção do biocombustível, onde ingressam novas tecnologias e, especialmente, os microrganismos manipulados geneticamente, entre outras possibilidades que possam inserir-se no quadro vantajoso já ocupado pelo etanol ${ }^{21}$. As incertezas que cercam as nanopartículas aplicadas aos alimentos, embalagens e produção agrícola também se aplicam aos biocombustíveis onde se adicionarem nanopartículas. Embora existam promessas de redução do consumo, a substituição das fontes fósseis, menor poluição e menos desgaste das peças dos veículos ${ }^{22}$, também serão necessárias mais respostas das ciências duras sobre os possíveis efeitos dessas nanopartículas em relação ao ser humano e ao meio ambiente. É preciso considerar o aprendizado coletivo gerado por experiências anteriores, respeitando as incertezas remanescentes iv ${ }^{23}$, devido à limitação dos dados disponíveis, desencadeando uma atitude proativa na gestão desses riscos, dentro do quadro que será estudado mais adiante neste trabalho.

O cenário apresentado, a partir dos exemplos das nanotecnologias aplicadas aos alimentos e biocombustíveis, mostra uma gama variada de riscos ainda sem uma devida fundamentação científica, mas com a produção já chegando ao mercado consumidor. Esse é o espaço privilegiado para

i Tradução livre dos autores.

ii Um estudo recente, publicado no mês de junho de 2012, realizado por pesquisadores da Duke University, mostrou como as partículas de nanoprata se comportam depois de lançadas no ecossistema, que foi simulado em miniatura pelos pesquisadores. As partículas acabaram se acumulando nas plantas, insetos e peixes que integraram esta miniatura de ecossistema. O mais interessante é que as nanopartículas de prata já são usadas como agentes antimicrobianos em diversos bens utilizados pelos humanos como vestuário, especialmente meias, recipientes para guardar alimentos, produtos farmacêuticos, cosméticos, eletrônicos e equipamentos óticos.

iii Os nanotubos de carbono podem causar tumores no pulmão, conforme recente pesquisa de investigadores da NIOSH.

iv Um exemplo é o óxido de cério em nanoescala que é utilizado em catalisadores de veículos, em relação ao qual ainda não existem estudos conclusivos sobre a sua segurança e a avaliação dos riscos desenvolvida até o momento tem sido considerada inadequada. 
a discussão acerca dos marcos regulatórios. Juntamente à questão regulatória, também será necessário desenvolver metodologias, critérios e diretrizes para avaliação, gestão e comunicação dos riscos, para tomada de decisões sobre o presente-futuro dessas novas tecnologias.

Para tanto é imprescindível o desenvolvimento de ferramentas e informações científicas para fazer avaliações de risco informadas sobre essa tecnologia emergente. Como exemplo de esforço nesse sentido cita-se a Avaliação Ambiental Abrangente (Comprehensive Environmental Assessment - CEA), da agência ambiental norte-americana (US Environmental Protection Agency, US - EPA).

A figura apresenta ${ }^{2} 4$ a CEA em sua abordagem holística para avaliar as consequências ambientais de várias escolhas entre produtos químicos, produtos e tecnologias. A CEA pode ser usada para identificar e priorizar pesquisas para apoiar futuros esforços de avaliação e/ou contribuir para gestão dos riscos na tomada de decisões mais específicas. Oferece uma estrutura para organizar sistematicamente as informações, incorporando e construindo métodos analíticos, incluindo a análise convencional de ciclo de vida, avaliação da exposição, análise de risco e caracterização dos riscos ${ }^{24}$.
Cabe observar que qualquer decisão acerca de alguma nanopartícula deverá ser mensurada, avaliando-se a repercussão que ela poderá ter nestse conjunto de energias e forças reciprocamente instaladas pela natureza, questionando os meios e as condições ambientais onde as interações ocorrem e a partir das quais poderão emergir efeitos nanotoxicológicos desconhecidos. De qualquer modo, a avaliação ambiental deverá partir do ciclo de vida do produto, considerando as suas possibilidades de interação desde a matéria-prima, passando pela pesquisa e processo produtivo em escala industrial, a sua comercialização, consumo e descarte, incluindo as possibilidades de reciclagem. Não se poderá deixar de lado a exposição, o transporte e a transformação dos produtos, a fim de avaliar efetivamente os níveis de impactos em relação ao ser humano e ao meio ambiente. No desencadeamento do processo produtivo instalam-se novos desafios e riscos, atingindo especialmente o trabalhador, onde se inaugura uma nova fase de gestão.

Será necessária a gestão regulatória e a dos riscos. A regulação das nanotecnologias parece que inaugura uma nova forma de normatização, isto é, um conjunto multicêntrico de regras e princípios que deverão nortear a instalação segura e limpa dos produtos desenvolvidos a partir da escala nano.

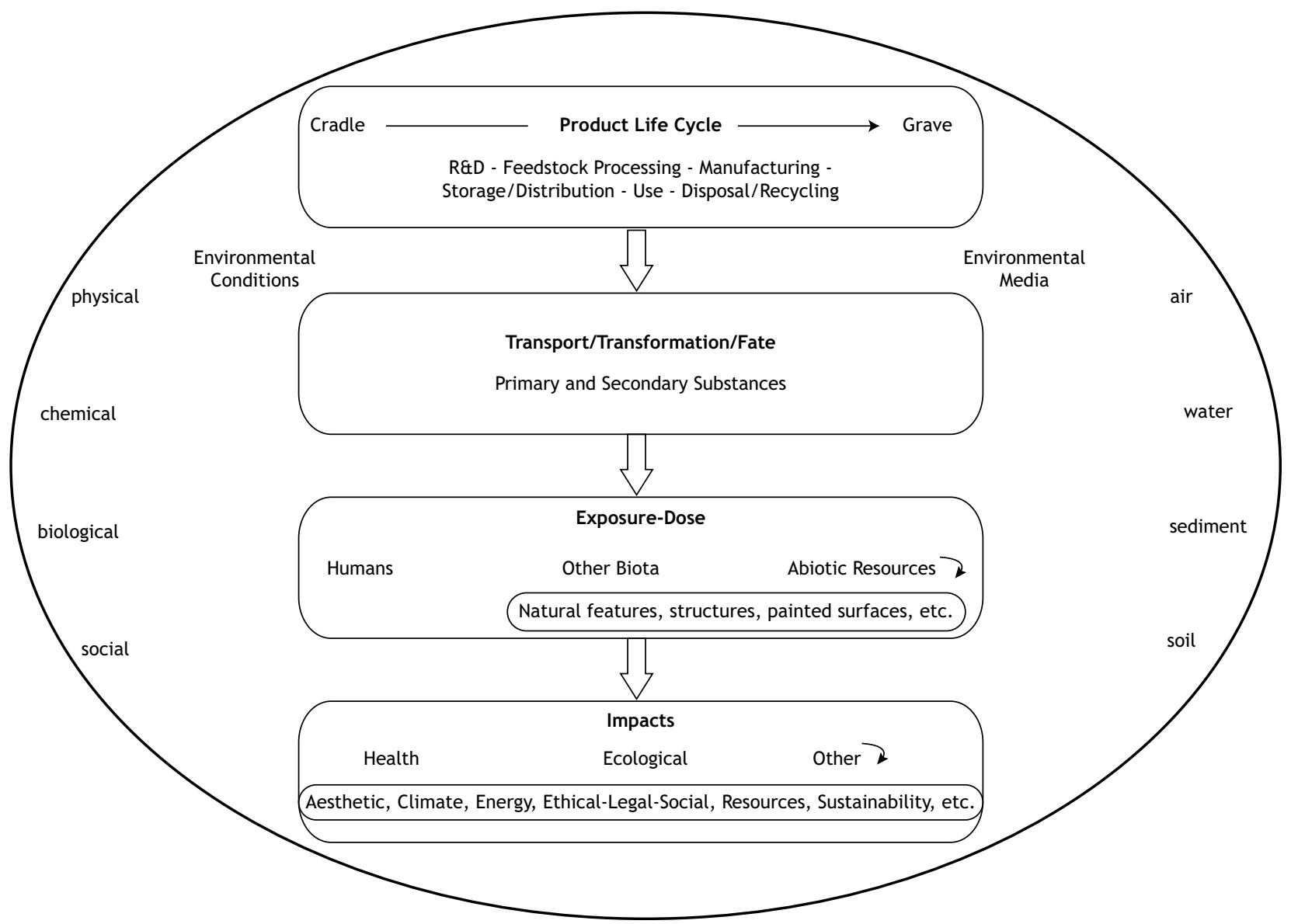

Figura 1. Resumo esquemático da Comprehensive Environmental Assessment (EPA) 
O termo regulação admite uma série de significados em diferentes áreas do conhecimento, como a cibernética, a economia, a política e o direito. No âmbito das ciências sociais o termo regulação é utilizado tradicionalmente para se referir à atividade estatal de produção de normas jurídicas, incluindo, além das leis, outros instrumentos juridicamente vinculantes (atos administrativos, como decretos, portarias, instruções normativas). A expressão regulação tem sido utilizada principalmente no contexto do direito regulatório, para denotar a atividade normativa das agências reguladoras.

Nos últimos anos, a regulação tem assumido um significado mais amplo, abarcando também instrumentos de metarregulação. Apesar de não existir definição acordada de autorregulação e metarregulação, em termos gerais pode-se afirmar que a primeira trata-se de um processo de regulação voluntária, instituído independentemente da regulamentação estatal, criada por atores não governamentais, inclusive por seu(s) próprio(s) destinatário(s), como é o caso das empresas, enquanto a segunda resulta da interação entre a regulação estatal e a autorregulação. A metarregulação seria uma estratégia de supervisão do Estado sobre os mecanismos da autorregulação. Trata-se de uma regulação em diferentes níveis, sendo que "cada camada regula a regulação da outra, em várias combinações de influência horizontal e vertical" 25 .

4 Discutindo o cenário regulatório a partir da inovação e das incertezas trazidas pela escala nanométrica

Diante desse ambiente dinâmico e incerto, ampliam-se os debates sobre se e como regular a nanotecnologia na internet, nas manifestações de grupos da sociedade civil organizada, na literatura científica, em conferências (reuniões entre pesquisadores, agentes governamentais, representantes de empresas) e audiências públicas, embora a grande imprensa não dê a devida atenção sobre o tema.

No sentido oposto, pesquisadores e representantes do setor empresarial criticam a possibilidade de respostas legais a partir das tradicionais normas de comando e controle (comand-and-control regulation), que não responderiam de forma adequada às aceleradas mudanças tecnológicas, devido à dificuldade de adaptação a situações de incerteza e à complexidade envolvida. Esses profissionais propõem estratégias de governança dos riscos da inovação da ciência de ponta e das tecnologias emergentes por meio de normas voluntárias, principalmente com base em instrumentos de autorregulação estabelecidos e aplicados individual ou conjuntamente por organizações profissionais, instituições de normatização técnica, corporações transnacionais ou organizações não governamentais.

Em 2005, o Projeto sobre Nanotecnologias Emergentes (Project on Emerging Nanotechnologies - PEN) do Woodrow Wilson International Center for Scholars, sediado nos Estados Unidos, divulgou o relatório Managing the Effects of Nanote- chnology, de autoria de J. Clarence Davies. No estudo, baseado na legislação dos EUA, Davies constatou a inadequação da legislação do país para dar conta das propriedades únicas e dos riscos dos nanomateriais e concluiu que um novo quadro regulamentador seria necessário ${ }^{26}$.

No continente europeu, a Comunicação da Comissão Europeia, de 17 de junho de 2008, intitulada "Aspectos regulamentares dos nanomateriais” ${ }^{27}$, concluiu que: a) a legislação em vigor abrange, em princípio, os riscos pertinentes relativos aos nanomateriais; (b) a proteção da saúde, da segurança e do ambiente tem de ser reforçada, principalmente através da melhoria da aplicação da legislação em vigor, quando, devido à falta de dados e métodos adequados para avaliar os riscos relativos aos nanomateriais, é efetivamente incapaz de resolver os seus riscos.

Em resposta, o Parlamento Europeu, em 2009, aprovou a "Resolução sobre Aspectos Regulamentares dos Nanomateriais" ${ }^{28}$, apresentada pela Comissão do Meio Ambiente, da Saúde Pública e Segurança Alimentar, que alerta para a insuficiência da legislação comunitária em vigor e para a necessidade de: a) rever toda a legislação pertinente no prazo de dois anos, para garantir a segurança para todas as aplicações de nanomateriais em produtos com impactos potenciais sobre a saúde, ambiental ou de segurança durante o seu ciclo de vida; b) garantir que as disposições legislativas e instrumentos de aplicação reflitam as particularidades de nanomateriais para que os trabalhadores, consumidores e/ou o ambiente possam ser expostos.

Em 3 de uutubro de 2012 foi publicada uma nova análise da Comissão Europeia sobre a regulamentação dos nanomateriais, a "Segunda revisão regulamentar relativa a nanomateriais" v 29,30. As conclusões da Comissão Europeia na Segunda Revisão Regulamentar relativa a Nanomateriais receberam uma série de críticas da sociedade civil organizada. Uma coalizão de organizações não governamentais redigiu uma carta aberta aos responsáveis pelas conclusões da referida revisão regulamentar criticando-os por: não considerarem de forma consistente informações científicas disponíveis sobre a existência de possíveis riscos decorrentes da exposição aos nanomateriais, notadamente no documento intitulado "Staff Working Paper (SWP)" ${ }^{31}$, elaborado por cientistas a pedido da Comissão Europeia; por considerarem insuficientes as alterações limitadas aos anexos do REACH, o que é insatisfatório para preencher lacunas existentes e para superar a atual falta de informações sobre os nanomateriais em produtos; por se recusarem "à implementação de uma abordagem de precaução", assim “colocando os interesses da indústria à frente do bem-estar da sociedade" 32 .

Percebe-se forte tensão entre os posicionamentos da Comissão Europeia e do Parlamento Europeu, como resultado da composição e dos interesses representados em ambas as

v Dentre as principais conclusões da Comissão Europeia na Segunda destacam-se a ideia de que: "Os nanomateriais requerem uma avaliação. À luz dos atuais conhecimentos e pareceres dos comitês científicos e consultivos da UE e dos avaliadores de riscos independentes, os nanomateriais são semelhantes aos produtos químicos ou às substâncias normais, em que alguns (ou algumas) podem ser tóxico(a)s e outro(a)s não. Os riscos possíveis estão relacionados com nanomateriais específicos e utilizações específicas. Por conseguinte, os nanomateriais requerem uma avaliação dos riscos, que deverá ser efetuada caso a caso, utilizando informações pertinentes. Os atuais métodos de avaliação dos riscos são aplicáveis, mesmo que ainda sejam necessários trabalhos sobre aspetos específicos da avaliação dos riscos..." 
instâncias, com forte peso na segunda a atuação do partido verde.

A seguir são apresentadas as possíveis opções relativas à regulação das nanotecnologias, aplicáveis aos alimentos e biocombustíveis ${ }^{33}$ :

\section{a) Optar pela não regulação}

A primeira opção leva ao caminho da não regulação imediata, diante da falta de comprovação científica dos riscos e dos danos atribuídos às nanotecnologias. Essa é a situação atual na maioria dos Estados nacionais, pois em seus sistemas legais não existem normas relativas a qualquer forma de rotulagem, fiscalização e informação sobre riscos específicos da nanotecnologia. Em muitos, sequer existe o debate público sobre o tema. Esperar a certeza científica dos impactos negativos da nanotecnologia para estabelecer marcos legais ou para revisar as leis existentes não parece ser a decisão mais adequada. Os diversos atores envolvidos devem ao menos proporcionar o debate sobre as medidas necessárias enquanto resposta aos riscos das nanotecnologias.

No caso da liberação de nanopartículas no meio ambiente, diversos estudos recomendam que não deva ser adiada a intervenção direta do Estado na criação de instrumentos de gestão de riscos que podem englobar a pesquisa dos impactos indesejados de tais resíduos, o monitoramento dos riscos, a limitação das atividades e, conforme as condições de incerteza e gravidade dos riscos potenciais, a proibição da venda ou da liberação de nanopartículas no meio ambiente.

b) Decretar uma moratória sobre pesquisa, desenvolvimento e comercialização de nanotecnologias e/ou nanomateriais:

Uma possibilidade no sentido oposto da não regulação seria a imposição de uma moratória global à pesquisa e comercialização de nanotecnologia/nanomaterias, defendida principalmente por organizações não governamentais ambientalistas. As ONGs Friends of the Earth Australia ${ }^{34}$ e Grupo ETC ${ }^{35}$ pedem uma moratória para o uso da nanotecnologia na agricultura e na produção de bens alimentares. A moratória sobre a nanotecnologia seria um exemplo da aplicação da versão mais extrema do princípio da precaução, na qual se exige que nenhuma substância seja liberada sem que antes seja provado que não será perigosa para o meio ambiente. Contudo, essa não é a única forma de aplicação do princípio da precaução.

Percebe-se que no caso da nanotecnologia tanto o caminho da não regulação como uma moratória genérica não representam respostas adequadas aos riscos incertos da nanotecnologia. 0 princípio da precaução traz a reflexão de que algo deve ser feito, mas em virtude da complexidade que envolve o amplo espectro de inovações, nos diferentes campos de aplicação da nanotecnologia, em virtude dos possíveis riscos decorrentes, exigem-se respostas plurais adequadas às suas particularidades, seja modificando/complementando as normas existentes, seja elaborando novos marcos regulatórios ou adotando/reconhecendo normas voluntárias estatais e privadas como complementares.

c) O lançamento de um processo incremental utilizando estruturas legislativas existentes:
Um meio termo entre as posições anteriores seria utilizar as estruturas legislativas existentes, capacitar os órgãos e agências governamentais para aplicar tais normas às peculiaridades da nanotecnologia, quando "necessário" proceder à revisão e alteração das normas jurídicas para se adaptar às novas exigências dos riscos nanotecnológicos. Esse processo não se apresenta tão radical e representa um caminho mais curto do que o lançamento de um abrangente e profundo processo regulatório específico para nanotecnologias, pois estaria focando as ações em alterações pontuais na legislação existente de mais fácil consenso político.

Como já foi dito, na maioria dos ordenamentos jurídicos nacionais e no Direito Internacional não existe menção à proteção específica contra os riscos das nanotecnologias. Entretanto, levando-se em conta as diversas normas jurídicas voltadas para a proteção do meio ambiente e da saúde humana, e a pluralidade de abordagens do risco pelo Direito, não se deve descartar a possibilidade ou de aplicar as leis existentes ou de adaptá-las às peculiaridades da nanotecnologia. Normas relativas ao controle de substâncias tóxicas, da biotecnologia, de alimentos, remédios, diplomas de Direito do Consumidor, Direito Civil, Direito Penal e Direito Ambiental, embora não apresentem atualmente um tratamento diferenciado que merecem os riscos e as peculiaridades das nanotecnologias, não devem ser ignorados. 0 conjunto (ou rede) atual das normas voltadas para o risco nas relações de consumo, nas questões ambientais e na saúde humana, embora não expresse diretamente cuidados com os riscos nanotecnológicos, não pode ser negligenciado, entre outros motivos, por explicitar importantes princípios como a precaução, a prevenção e o direito à informação. Ademais, seja qual for a solução dada para a regulação da nanotecnologia - modificação ou a criação de novos marcos regulatórios -, é importante a análise das normas existentes, pois uma nova norma não vai se inserir em um sistema paralelo, autônomo, próprio das nanotecnologias.

É crucial partir do contexto atual do Direito e avaliar em quais situações é apropriado promover alterações pontuais ou amplas para incorporar novos critérios, novas exigências. Nesse sentido é importante o estudo de Direito Comparado, como uma forma de "prospecção" em realidades diferentes para tomada de decisões (se, quando e como legislar?) no contexto nacional.

d) 0 lançamento de um abrangente e profundo processo regulatório específico para nanotecnologias:

Um exemplo de controle de informações específicas sobre nanoprodutos pode ser retirado da legislação francesa. Os artigos L523-1 a L-523-3 do Código Ambiental francês preveem a obrigação de declarar as quantias e os usos de nanopartículas, produzidas, distribuídas ou importadas na França. A determinação tem por objetivo o melhor conhecimento dessas substâncias e seus usos, o controle dos campos de utilização, um melhor conhecimento do andamento dos volumes comercializados e, enfim, coletar informações disponíveis sobre suas propriedades toxicológicas e ecotoxicológicas. Para regulamentar os dispositivos do Código Ambiental francês sobre o tema, entrou em vigor, em janeiro de 2013, o Decreto $n^{\circ} 2012$ - 
232, de 17 de fevereiro de 2012, que prevê declaração anual de "substâncias no estado de nanopartículas".

No que diz respeito à regulação de nanomateriais em alimentos, o regulamento relativo à informação alimentar para os consumidores da União Europeia (UE Regulamento 1169/2011) foi aprovado pela CE em julho de 2011 e entrará em vigor em dezembro de 2014, combinando duas diretivas anteriores sobre "rotulagem, apresentação e publicidade dos gêneros alimentícios" (2000/13/CE) e "rotulagem nutricional dos gêneros alimentícios" (90/496/CEE). Esse regulamento inclui a exigência de rotulagem dos ingredientes na forma de nanomateriais em alimentos. Segundo o regulamento: "Os ingredientes contidos sob a forma de nanomateriais artificiais devem ser claramente indicados na lista de ingredientes. A palavra 'nano' entre parênteses deve figurar a seguir aos nomes destes ingredientes" vi.

No Brasil já foram propostos três projetos de lei no Congresso Nacional, o Projeto de Lei $n^{\circ} 5.076 / 2005$ e o Projeto de Lei $n^{\circ} 131 / 2010$, ambos arquivados, respectivamente, em 2007 e 2013, além do Projeto de Lei $n^{\circ}$ 5133, de 2013, em tramitação.

O primeiro projeto arquivado, o PL $n^{\circ} 5.076 / 2005$, proposto pelo deputado Edson Duarte, que visava à criação de dispositivos legais de "nano-segurança", foi arquivado em janeiro de 2007, devido à aprovação unânime do parecer do relator Léo Alcântara pela Comissão Desenvolvimento Econômico, Indústria e Comércio da Câmara dos Deputados. No entendimento da comissão, o Brasil não está no momento nem no contexto certo para regulamentar por lei a nanotecnologia, pois "no atual estágio do desenvolvimento da nanotecnologia do País, não é nem mesmo clara a abrangência do objeto de análise que se propõe regulamentar". Segundo Alcântara, "regulamentar por via legal algo cujos processos e produtos ainda pouco se conhecem gera elevado risco de ampliar a incerteza dos investidores, inibindo o fluxo de investimentos nessa atividade". 0 relator entendeu que as preocupações do autor do projeto já estão contempladas em normas existentes no País. No parecer o relator afirma também que "a proposta aduziria uma série de burocracias a mais que implicariam o aumento do chamado 'custo Brasil' nessa atividade que apenas agora está começando a se firmar no País". Segundo o texto, aprovar a proposição poderia "significar a diferença na escolha do empresário entre investir ou não nessa área de fronteira do conhecimento" ${ }^{36}$.

O outro projeto rejeitado, o PL $n^{\circ} 131$, de 2010, visava alterar o Decreto-Lei $n^{\circ} 986$, de 21 de outubro de 1969, que institui normas básicas sobre alimentos, e a Lei $n^{\circ} 6.360$, de 23 de setembro de 1976, relativa à vigilância sanitária a que ficam sujeitos os medicamentos, as drogas, os insumos farmacêuticos e correlatos, cosméticos, saneantes. Se aprovado, promoveria alteração no texto do Decreto-Lei $n^{\circ} 986$, de 21 de outubro de 1969, para determinar que os rótulos, as bulas, os impressos, as etiquetas, as embalagens, os prospectos e os materiais publicitários referentes aos produtos, medicamentos, drogas, insumos farmacêuticos e correlatos, cosméticos, saneantes que tenham sido elaborados com recurso à nanotecnologia, tragam a informação de maneira ostensiva sobre esse fato. A justificativa do projeto destaca a importância da nanotecnologia no desenvolvimento de novos produtos e o crescimento de nanoprodutos que já estão no mercado.

Durante a tramitação, a proposição foi submetida à análise da Comissão de Assuntos Sociais e à análise da Comissão de Meio Ambiente, Defesa do Consumidor, Controle e Fiscalização. Ambas as comissões manifestaram-se pela rejeição do PL $n^{\circ} 131$, de 2010, entendendo-o como uma proposta de intervenção legal desnecessária sobre a produção de alimentos e demais produtos referidos. Segundo o relatório, não há base científica para a exigência dessas informações; além disso, o Projeto poderia causar confusão e alarmes desnecessários ao consumidor, e prejuízos econômicos às empresas. Ademais, os parlamentares das comissões entenderam que tal exigência não deveria constar em uma lei ordinária, pois a ANVISA possui competência para regular a matéria, através de norma infralegal.

Atualmente, encontra-se em tramitação o Projeto de Lei $n^{\circ}$ 5133, de 2013, de autoria de Sarney Filho, do PV. Essa proposição tem o objetivo de tornar obrigatória a rotulagem de produtos que fazem uso de nanotecnologia. A justificativa apresentada para a rotulagem é direito de informação ao consumidor sobre possíveis riscos dos produtos "obtidos por processo nanotecnológico".

A proposição referida determina que a informação deve ser colocada no rótulo de produtos que sejam obtidos por processos nanotecnológicos, ou que contenham nanopartículas (ingredientes nanotecnológicos) em sua composição, ou que sejam produzidos a partir de processo de nanotecnologia, ou alimentos ou ingredientes produzidos com animais que receberam ração com nanoprodutos. Essa informação se aplica a cosméticos, fármacos e alimentos.

O Projeto de Lei $n^{\circ} 6.741$ de 2013, também de autoria do Deputado Federal Sarney Filho, do PV, propõe a criação de uma política pública nacional de gestão dos riscos do desenvolvimento da nanotecnologia, observados os princípios da informação, transparência, participação social, precaução, prevenção e responsabilidade social. Para a implementação da Política Nacional de Nanotecnologia, o referido projeto de lei indica quatro instrumentos: a) o cadastro nacional para o controle e o acompanhamento de projetos de pesquisa, desenvolvimento tecnológico, geração, comercialização e inserção no mercado de nanoprodutos; b) a autorização do Poder Público no que se refere à saúde humana, animal e ambiental para a pesquisa, produção e comercialização de nanoprodutos ou derivados de

vi $O$ texto do Regulamento 1169/2011 da União Europeia traz o conceito de "nanomaterial artificial”, como sendo: "qualquer material intencionalmente produzido com uma ou mais dimensões da ordem de $100 \mathrm{~nm}$ ou menos, ou composto por partes funcionais diversas, internamente ou à superfície, muitas das quais têm uma ou mais dimensões da ordem de $100 \mathrm{~nm}$ ou menos, incluindo estruturas, aglomerados ou agregados que, conquanto possam ter uma dimensão superior a $100 \mathrm{~nm}$, conservam propriedades características da nanoescala. As propriedades características da nanoescala incluem: i) as que estão relacionadas com a grande área de superfície específica dos materiais considerados; e/ou ii) propriedades físico-químicas específicas que divergem das da não-nanoforma do mesmo material." 
processos nanotecnológicos; c) a exigência de estudos de impacto ambiental para liberação de nanoprodutos no meio ambiente; d) o fomento à realização de estudos e pesquisas sobre os efeitos de nanoprodutos sobre a saúde humana e animal, e sobre o meio ambiente. 0 projeto de lei também visa impor planos de monitoramento específicos para processos e produtos nanotecnológicos, quando o poder público entender que estes possam causar danos ao meio ambiente ou à saúde humana ou animal. A mesma proposta legislativa também se refere: a) a possibilidade de indeferimento, suspensão e registro do processo ou produto da nanotecnologia, ou que contenha matéria-prima nanotecnológica, b) a disposição adequada de rejeitos da nanotecnologia (impondo a necessidade de planos de resíduos com base na Política Nacional de Resíduos Sólidos (Lei $n^{\circ} 12.305$, de 02 de agosto de 2010), c) o dever de notificação de acidentes envolvendo nanoprodutos (Lei $n^{\circ} 12.608$, de 10 de abril de 2012, que trata da Política Nacional de Proteção e Defesa Civil), d) a aplicação de recursos públicos em nanociência e nanotecnologia, e) a vedação do patenteamento de produtos ou processos nanotecnológico obtidos a partir de seres vivos e a proibição de a pesquisa, a utilização, a comercialização, o registro, o patenteamento e o licenciamento de nanotecnologias de restrição de uso, f) as responsabilidades e sanções relativas ao não cumprimento das medidas necessárias à prevenção e precaução dos inconvenientes e danos causados por atividades derivadas da nanotecnologia.

Devido às diversas aplicações, em áreas distintas da ciência e tecnologia e diferentes da economia, bem como aos bens jurídicos envolvidos (segurança, meio ambiente, propriedade, saúde, vida, liberdade), ações futuras relativas à regulamentação devem contemplar larga participação da sociedade, envolvendo distintas organizações interessadas e ampla divulgação de informação sobre o processo de formação das normas.

Contudo, diante do desafio do estabelecimento de normas jurídicas estatais "oficiais" para regular o desenvolvimento das nanotecnologias, percebe-se que existem "páginas em branco", que significam, ao mesmo tempo, a existência de diversos caminhos para a escolha e a aparente incapacidade de o sistema político responder de forma tradicional na criação de marcos legais obrigatórios diante dos riscos e da incerteza, na proporção em que as tecnologias avançam.

A inércia dos Estados no sentido de estabelecer um conjunto normativo para fazer frente aos riscos das nanotecnologias decorre tanto da incerteza generalizada em relação a essa tecnologia como da pressão por parte do setor privado, que vê na regulamentação estatal um entrave aos seus interesses. Esse cenário indica a tendência de as iniciativas estatais se restringirem ao estabelecimento de recomendações, guias de boas práticas ou a referendar tais iniciativas quando desenvolvidas e aplicadas por redes de organizações privadas. Uma regulação direta sobre as nanotecnologias envolve dois grandes problemas: não há consenso ou uniformidade na comunidade científica sobre a metodologia mais adequada para aferir os efeitos toxicológicos das nanopartículas e, além disso, não se sabe o número exato de nanopartículas já produzidas pela ação hu- mana. Essas duas dificuldades acabam dificultando, no curto prazo, qualquer tentativa para criar uma regulação nanotecnológica específica. Há um cuidado a se observar nesse ponto: a criação de normas específicas sem um adequado alinhamento com as diversas áreas do conhecimento envolvidas pode gerar mais dificuldades do que a sua ausência.

e) Basear-se em medidas voluntárias (soft law, autorregulação e metarregulação):

A expressão soft law emergiu no âmbito do Direito Internacional em contraposição a hard law, por representar normas que não possuem caráter sancionatório expresso. A maioria das iniciativas da soft law é concebida no âmbito de Organizações Internacionais envolvendo atividades econômicas, financeiras e temas emergentes na sociedade global, como proteção do meio ambiente, direitos humanos e regulação de novas tecnologias.

A soft law é muito criticada pelas dificuldades doutrinárias e contradições terminológicas, por não ser propriamente uma norma jurídica no sentido positivista, por não existirem de forma clara critérios de distinção entre direito e não direito. Também é atribuído à soft law o risco à soberania dos Estados, a partir da flexibilização das normas internacionais em favor da globalização econômica e do mercado.

A diferenciação binária positivista entre direito e não direito não serve para determinar a importância da soft law e sua influência no comportamento dos diversos destinatários da norma. A soft law não retira necessariamente sua força de uma suposta natureza jurídica, mas sim da prática social, como observa László Blutman: “É duvidoso que essas regras exigiriam uma forma jurídica para realizar suas funções de regulação eficiente. No entanto, as reflexões acadêmicas sobre a soft law geralmente cometem o erro de atribuir a todo custo algum tipo de natureza jurídica a essas normas, a fim de explicar as suas funções reguladoras. A resposta para a eficácia ou a ineficácia dessas normas, no entanto, não é, na maioria das vezes, encontrada nas coordenadas da sua relação com as regras legais formais, mas nas análises detalhadas das relações sociológicas internacionais" ${ }^{37}$.

O atual cenário da governança dos riscos da inovação da nanotecnologia está se estruturando com base em normas desprovidas de caráter sancionatório, em pelo menos duas grandes categorias de soft law: as "normas públicas" voluntárias, que servem como orientação para boas práticas científicas e empresariais, programas e guias governamentais voluntários (EPA, Nanoscale Materials Stewardship Program, DEFRA, Voluntary Reporting Scheme for Manufactured Nanomaterials, Código de Conduta da União Europeia para a investigação responsável no domínio das nanociências e das nanotecnologias), e "normas privadas" de autorregulação, guias de boas práticas elaborados e aplicados pela e na própria empresa para o manuseio seguro de nanomateriais (BASF, Code of Conduct Nanotechnology) ou em parceria com organizações não governamentais (DuPont \& Environmental Defense, Nano Risk Framework), códigos de conduta estabelecidos em um conjunto por diversas partes interessadas, Multi-Stakeholder Codes of Conduct (Responsible NanoCode), padrões e normas técnicas baseadas na 
expertise científica (normas da International Standards Organisation - ISO e da American Society for Testing and Materials - ASTM), European Commitee on Standardization (CEN), Organization for Economic Cooperation and Developmen (OECD), British Standard Institute (BSI) ${ }^{38}$.

Diante das dificuldades de regulação legal da matéria, dos custos econômicos e dos entraves às pesquisas provenientes da criação de novas instituições para fiscalização e regulamentação das nanotecnologias, os defensores da autorregulação entendem que seria melhor aproveitar as normas existentes para avaliação da segurança de novos produtos e substâncias e deixar de lado a busca por novos marcos regulatórios cogentes por parte do Estado. Paralelamente, desenvolver-se-ia a ação regulatória das organizações privadas (institutos de pesquisa, empresas, organizações não governamentais, instituições responsáveis pelo estabelecimento de normas técnicas e por certificar a conformidade com os padrões exigidos). Outros, entretanto, entendem que os códigos voluntários podem ser parte importante para uma "primeira tentativa de nova governança” ao regulamentarem rapidamente áreas emergentes, mas os governos devem desempenhar um papel central na governança dos riscos da(s) nanotecnologia(s), baseando-se em regulamentos "nanoespecíficos", no sentido de construir parte de uma "teia regulatória em evolução" ${ }^{39}$.

Em face do futuro incerto das nanotecnologias, que envolve uma complexidade muito grande de benefícios esperados e riscos temidos, optar por abordagens regulamentares do tipo soft law pode proporcionar benefícios importantes à experimentação e aprendizagem em uma ação regulatória gradual, que inicia com normas voluntárias e progressivamente abre espaço para as decisões relativas à incorporação de normas mais formais e cogentes (hard law) ${ }^{40}$.

Ademais, a soft law facilita o consenso relativo a compromissos de cooperação entre diversos atores sociais. A necessidade de lidar com interesses confrontantes e valores de atores não estatais tão díspares, como empresas transnacionais (ETNs) e organizações não governamentais (ONGs), está entre as razões pelas quais os Estados estão entre os interessados em promover estratégias de soft law ${ }^{41}$.

Nesse contexto, a soft law e, entre suas variantes, as normas de autorregulação privada devem ser pensadas como suplementares à legislação estatal, no sentido de antecipar obrigações futuras, gerar informação, estimular comportamentos, esclarecer e incentivar boas práticas, trazer oportunidades. Mas deve-se ter o cuidado para evitar que o recurso à soft law, principalmente a autorregulação, não seja transformada em instrumento de oposição ao controle externo estatal, como forma de "refrear o desenvolvimento legislativo" relativo às demandas públicas trazidas pela nanotecnologia. Por isso, iniciativas de governança baseadas na soft law devem ser transparentes e abertas ao controle do Estado e da sociedade civil, a partir de amplo acesso à informação; caso contrário, tendem a funcionar mais como "propaganda verde enganosa" (greenwashing) voltada a iludir consumidores, desmobilizar o poder estatal e afastar a sociedade da gestão dos riscos.
Recente estudo realizado nos Estados Unidos, entre 20082012, reforça análises anteriores, inclusive governamentais, de que há falta de transparência sobre essa questão ${ }^{15}$. A pesquisa concluiu que muitas empresas sequer sabem que existem nanomateriais em sua cadeia produtiva. Para realização desse estudo, feito pela "As You Sow", foram encaminhados 2.500 questionários a empresas do setor de alimentos, incluindo as maiores indústrias alimentícias, distribuidores, embaladores, varejistas, companhias de fast food e suplementos nutricionais. Somente 26 companhias responderam à pesquisa ${ }^{15}$. Como se pode exigir que seja observado o direito à informação do consumidor, se o próprio fabricante, comerciante, desconhece ou se nega a repassar informações sobre a aplicação de nanotecnologia em seus produtos? Como é possível que as agências e demais órgãos façam a sua parte - estimando, sistematizando e estudando possíveis efeitos tóxicos -, se as empresas sonegam essas importantes informações? Pode-se esperar que as empresas, ao assumirem compromissos voluntários, apresentem todos os dados, especialmente aqueles que podem ser interpretados como alertas de risco em relação às pesquisas, ao desenvolvimento tecnológico por elas desenvolvido e aos seus produtos por elas comercializados?

Em virtude das dificuldades da regulação estatal tradicional, imposta através de instrumentos de comando e controle para responder de forma satisfatória às incertezas resultantes do desenvolvimento tecnológico, bem como as falhas comuns nas estratégias de autorregulação (falta de transparência e legitimidade), ressalta-se a pertinência do debate em torno de novos instrumentos de metarregulação, para agregar às estratégias de governança dos riscos da nanotecnologia uma melhor comunicação entre sociedade civil, Estado, empresas e cientistas ${ }^{25}$. Na metarregulação, o Estado não delega ao setor privado toda a regulação, ao mesmo tempo em que não avoca para si todo o controle, mas implica em estratégias de supervisão do Estado dos mecanismos de autorregulação privada.

Os meios convencionais de comando e controle geralmente requerem informações sobre os riscos criados por determinados produtos ou modos de produção. Os reguladores precisam conhecer a magnitude do dano potencial e a probabilidade de ocorrência de danos. No caso do desenvolvimento das nanotecnologias, organizações reguladoras estatais tendem a encontrar-se em desvantagem em obter informações significativas em comparação com as indústrias que elas supervisionam. Segundo Coglianese e Mendelson ${ }^{25}$, em casos de complexidade ou risco emergente, a autorregulação e metarregulação podem trazer vantagens quanto a recursos e informações necessárias para regular, mas isso não quer dizer que elas sejam soluções perfeitas. Dito de outra forma, o recurso à metarregulação pode ser a melhor opção ou a opção disponível em determinadas circunstâncias que envolvam desenvolvimento acelerado e incertezas científicas quanto aos riscos, mesmo que não representem o ideal. Para Coglianese e Mendelson ${ }^{25}$, o principal problema com a autorregulação e metarregulação reside no fato de que, mesmo em situações nas quais as empresas tenham as melhores informações para encontrar soluções para 
problemas concernentes ao interesse público, não necessariamente terão incentivos para tanto ${ }^{25}$. Afinal, "se esses incentivos fossem suficientes, nenhuma regulamentação seria necessária". Em termos práticos, para eles um grande desafio a ser enfrentado pela autorregulação e metarregulação será garantir que as metas estipuladas para o uso do poder discricionário dispensado às empresas sejam implantadas de forma consistente com objetivos de regulação pública, mais do que com seus próprios interesses individuais privados 25 .

Uma importante questão que acompanha o desenvolvimento da nanotecnologia é saber se a metarregulação efetivamente representa um meio termo entre os instrumentos de comando e controle estatais e a autorregulação privada, na medida em que se comprove ser mais flexível e adaptável às incertezas científicas que os primeiros, bem como mais confiável e transparente do que a segunda.

\section{Resultados e discussão}

Conforme se verificou neste estudo, a incerteza sobre os efeitos das nanotecnologias envolve a participação de diversos atores sociais (empresas, organizações não governamentais, organizações internacionais, cientistas e Estados) e tem gerado uma série de textos não oficiais, como relatórios, guias de boas práticas e recomendações. Diferentemente, a resposta regulatória oficial dos Estados, através da promulgação de legislação cogente relativa aos riscos da nanotecnologia, é a exceção.

Em resposta à questão proposta por este estudo, observa-se que no caso da nanotecnologia se forma uma pluralidade de redes complexas de regulação (incluindo autorregulação e metarregulação) que estruturam diferentes formas de governança dos riscos, envolvendo distintos atores sociais, governamentais, atores estatais ou não estatais.

Como resultado preliminar da avaliação sobre as opções relativas à regulação dos riscos das nanotecnologias, incluindo alimentos e biocombustíveis, percebe-se que as formas tradicionais de regulação estatal baseadas em instrumentos de "comando e controle" são a exceção, restritas a algumas iniciativas relativas ao fornecimento de informações, por meio da exigência legal de registro de substâncias e produtos que contenham nanopartículas ou pela rotulagem de produtos alimentícios. São iniciativas muito importantes para garantia do direito à informação do consumidor e dos cidadãos. Nesse sentido, o arquivamento do PL n ${ }^{\circ} 131$ de 2010 representou a perda da oportunidade de estabelecer uma norma pertinente para proteger o direito de escolha informada do consumidor.

Já o recurso à soft law, notadamente as medidas voluntárias de autorregulação e metarregulação, podem trazer benefícios, quando concebidas e aplicadas para serem complementares às normas estatais cogentes que protegem direitos básicos dos cidadãos e consumidores, no sentido de: a) provocar o cumprimento de obrigações, para além das impostas pela legislação existente; b) originar e difundir informação; c) estimular comportamentos preventivos (gestão dos ricos) entre atores privados.

\section{Referências}

1. Kerchove MV, Ost F. De la pyramide au réseau? Pour une théorie dialectique du droit. Bruxelles: Publications des Facultés universitaires Saint-Louis; 2000.

2. Kelsen H. Teoria Pura do Direito. 5. ed. São Paulo: Martins Fontes; 1996.

3. Echeverría J. Interdisciplinariedad y convergencia tecnocientífica nano-bio-info-cogno. Sociologias. 2009;11(22):22-53.

4. Maldonado CE. Filosofia de la Ciencia y Nanotecnociencia. In: Gallo JG, González E, Baquero-Gómez F (editores). Nanotecnociencia: nociones preliminares sobre el universo nanoscópico. Bogotá: Ediciones Buinaima; 2007. p. 70-1.

5. Engelmann W. A nanotecnociência como uma revolução científica: os direitos humanos e uma (nova) filosofia na Ciência. In: Streck L, Morais JLB (organizadores). Constituição, Sistemas Sociais e Hermenêutica: Anuário do Programa de Pós-Graduação em Direito da UNISINOS: Mestrado e Doutorado. Porto Alegre: Livraria do Advogado; 2010. p. 249-65.

6. Drexler E. Os nanossistemas: possibilidades e limites para o planeta e para a sociedade. In: Neutzling I, Andrade PFC (organizadores). Uma sociedade pós-humana: possibilidades e limites das nanotecnologias. São Leopoldo: Unisinos; 2009. p. 42.

7. Engelmann W, Flores AS, Weyermüller AR. Nanotecnologias, marcos regulatórios e direito ambiental. Curitiba: Honoris Causa; 2010.

8. Guimarães AS. O Corpo Expandido. Filosofia Ciência \& Vida. 2008;3(28):16-25.

9. Pittella JE. Construindo o saber da Ciência. Belo Horizonte: COOPMED; 2012. p. 63.

10. Gray KA. Five myths about nanotechnology in the current public policy debate: a science and engineering perspective. In: Dana DA (editor). The nanotechnology challenge: creating legal institutions for uncertain risks. New York: Cambridge University Press; 2012. p. 11-60.

11. Malloy TF. Soft law and nanotechnology: a functional perspective. Jurimetrics. 2012;52(3):1-12.

12. Shatkin JA. Assessing nanotecnology health and environmental Risks. In: Nanotechnology: health and environmental risks. 2. ed. New York: CRC Press; 2013. p.25-8.

13. Shatkin JA. Defining risk assessment and how it is used for environmental protection and its potencial role for managing nanotecnology risks. In: Nanotechnology: health and environmental risks. 2. ed. New York: CRC Press; 2013. p. 32-5.

14. Keller KH. Nanotechnology and society. In: Maynard AD, Pui DYH (editores). Nanoparticles and occupational health. New York: Springer; 2007. p. 5-6.

15. Behar A, Fugere D, Passoff M. Slipping through the cracks: an issue briefs on nanomaterials in food [Internet]. Oakland, CA: As You Sow; 2013. [acesso em 20 jul. 2013]. Disponível em: http://www.corporatecrimereporter.com/ wp-content/uploads/2013/02/SlippingThroughTheCracks-2013.pdf 
16. Lowry GV, Espinasse BP, Badireddy AR, Richardson CJ, Reinsch BC, Bryant LD, Bone AJ, Deonarine A, Chae S, Therezien M, Colman BP, Hsu-Kim H, Bernhardt ES, Matson CW, Wiesner MR. Long-term transformation and fate of manufactured ag nanoparticles in a simulated large scale freshwater emergent wetland. Environ Sci Technol. 2012;46(13):7027-36.

17. Food and Agriculture Organization of The United Nations, World Health Organization. Expert Meeting on the Application of Nanotechnologies in the Food and Agriculture Sectors: Potential Food Safety Implications [Internet]. Rome: FAO/WHO; 2010. [acesso em 28 jul. 2013]. Disponível em: http://whqlibdoc.who.int/publications/2010/9789241563932_eng.pdf

18. Castranova VG, Charles L, Schulte P. New Findings on Lung Tumor Formation in Laboratory Mice Exposed to Multi-Walled Carbon Nanotubes [Internet]. NIOSH; 2013. [acesso em 28 jul. 2013]. Disponível em: http://blogs.cdc.gov/niosh-science-blog/2013/03/11/mwcnt/

19. Khodakovskaya M, Dervishi E, Mahmood M, Xu Y, LI Z, Watanabe F, Birit AS. Carbon nanotubes are able to penetrate plant seed coat and dramatically affect seed germination and plant growth. ACS Nano. 2009;3(10):3221-7.

20. Organisation for Economic Co-Operation and Development. Small sizes that matter: oportunities and risks of nanotechnologies [Internet]. Paris: OECD; 2005. [acesso em 29 jul. 2013]. Disponível em: http://www.oecd.org/ chemicalsafety/nanosafety/44108334.pdf

21. Duailibe AK. A Realidade dos Biocombustíveis no Brasil. Scientific America Brasil. 2012;11(21):32-9.

22. Basha JS, Anand RB. Role of nano additive blended biodiesel emulsion fuel on the working characteristics of a diesel engine. J Renew Sust Energ Rev. 2011;3(2):1-17.

23. Shatkin JA. Sustainable nanotechnology development using risk assessment and applying life cycle thinking. In: Nanotechnology: health and environmental risks. 2. ed. New York: CRC Press; 2013. p. 61-66.

24. United States Enrivonmental Protection Agency. Comprehensive environmental assessment: a meta-assessment approach to increase effectiveness of risk management and research planning [Internet]. United States: EPA; 2013. [acesso em 29 jul. 2013]. Disponível em: http:/ /www.epa. gov/nanoscience/files/CEAPrecis.pdf

25. Coglianese C, Mendelson E. Meta-Regulation and Self-Regulation. In: Baldwin R, Cave M, Lodge $M$ (editores). The Oxford Handbook of Regulation. Oxford: 2010. p. 146-68.

26. Davies JC. Managing the effects of nanotechnology [Internet]. Washington DC: Woodrow Wilson International Center for Scholars; 2006. [acesso em 20 jul. 2013]. Disponível em: http://www.nanotechproject.org/process/ files/2708/30_pen2_mngeffects.pdf

27. Comissão Europeia. Parecer do Comitê Econômico e Social Europeu sobre a Comunicação da Comissão ao Parlamento Europeu, ao Conselho e ao Comitê Econômico e Social Europeu: aspectos regulamentares dos nanomateriais [In- ternet]. Jornal Oficial da União Europeia C 218/21, 11 set. 2009. 6 p. [acesso em 14 jun. 2013]. Disponível em: http: / / eur-lex.europa.eu/LexUriServ/LexUriServ.do?uri=0 $\mathrm{J}: \mathrm{C}: 2009: 218: 0021: 0026: P T: P D F$

28. Parlamento Europeu. Comissão do Ambiente da Saúde Pública e da Segurança Alimentar. Relatório sobre aspectos regulamentares dos nanomateriais (2008/2208(INI) [Internet]. 2009. [acesso em 15 maio 2013]. Disponível em: http:// www.europarl.europa.eu/sides/getDoc.do?pubRef=-//EP// TEXT+REPORT+A6-2009-0255+0+DOC+XML+V0//PT\#title1

29. Comissão Europeia. Comunicação da Comissão ao Parlamento Europeu, ao Conselho e ao Comitê Econômico e Social Europeu: segunda revisão regulamentar relativa a "nanomateriais" [Internet]. Bruxelas: Comissão Europeia; 2012. (n. 572 final). [acesso em 14 jun. 2013]. Disponível em: http://eur-lex.europa.eu/LexUriServ/LexUriServ. do?uri=COM:2012:0572:FIN:PT:PDF

30. Comissão Europeia. Nanomateriais: Abordagem de segurança caso a caso para tecnologias inovadoras [Internet]. Bruxelas: Comissão Europeia; 2012. [acesso em 13 jul. 2013]. Disponível em: http://europa.eu/rapid/press-release_IP-12-1050_pt.htm

31. European Commission. Types and uses of nanomaterials, including safety aspects [Internet]. Brussels: European Comission; 2012. (n. 288 final). [acesso em 18 maio 2013]. Disponível em: http://ec.europa.eu/nanotechnology/ pdf/second_regulatory_review_on_nanomaterials_-_staff_working_paper_accompanying_com(2012)_572.pdf

32. Stakeholders' Response to the Communication on the Second Regulatory Review on Nanomaterials [Internet]. Brussels: European Environmental Citizens Organisation for Standardisation; 2012. [acesso em 19 jul. 2013]. Disponível em: http://www.ecostandard.org/wp-content/uploads/ Nanomaterials-joint-letter-23-10-2012-logos.pdf

33. European Commission. Nanotechnologies: a preliminary risk analysis on the basis of a preliminary workshop organized in Brussels on 1-2 March 2004 by the Health and Consumer Protection Directorate General of the European Commission [Internet]. 2004. [acesso em 10 jul. 2013]. Disponível em: http://ec.europa.eu/health/ph_risk/documents/ev_20040301_en.pdf

34. Friends of the Earth. Out of the Laboratory and on to our Plates. Nanotechnology in Food \& Agriculture [Internet]. United States; 2008. [acesso em 29 jul. 2013]. Disponível em: http://nano.foe.org.au/sites/default/files/Nanotechnology $\% 20$ in $\% 20$ food $\% 20$ and\%20agriculture $\% 20-\% 20$ text $\% 20$ only\%20version_0.pdf

35. Grupo ETC. Manual de Bolso das Tecnologias em Nanoescala ... e a teoria do "little bang" [Internet]. Canada: Etcgroup; 2005. [acesso em 15 jul. 2013]. Disponível em: http: / /www.etcgroup.org/sites/www.etcgroup.org/files/ publication/57/01/tinyp_portuguesfinal.pdf

36. Brasil, Câmara dos Deputados. Comissão de Desenvolvimento Econômico, Indústria e Comércio. Projeto de Lei $n^{\circ}$ 5.076-C, de 2005. Dispõe sobre a pesquisa e o uso da nanotecnologia 
no País, cria Comissão Técnica Nacional de Nanossegurança - CTNano, institui Fundo de Desenvolvimento de Nanotecnologia - FDNano, e dá outras providências [Internet]. Brasília: Câmara dos Deputados; 2005. [acesso em 02 mar. 2013]. Disponível em: www.camara.gov.br/sileg/integras/337343.doc

37. Blutman L. In the trap of a legal metaphor: international soft law. Int Comp. Law Qual. 2010;59(3): 605-24.

38. Shatkin JA. Ongoing International Efforts to Address Risk Issues for Nanotechnology. In: Nanotechnology: health and environmental risks. 2. ed. New York: CRC Press, 2013.
39. Bowman DM, Hodge GA. Governing Nanotechnology without Government? Sci Public Policy. 2008;35(7):475-87.

40. Marchant G, Sylvester D, Abbott K. A new soft law approach to nanotechnology oversight: a voluntary product certification scheme [Internet]. UCLA J. Envtl. L. \& Pol'y. 2009 [acesso em 30 jul. 2013]; 28 (123). Disponível em: http:// papers.ssrn.com/sol3/Delivery.cfm/SSRN_ID1483910_ code336250.pdf?abstractid=1483910\&mirid $=1$

41. Abbott K, Snidal D. Hard and soft law in international governance. Int Org. 2000;54:421-56.

Data de recebimento: $31 / 07 / 2013$

Data de aceite: 19/11/2013 